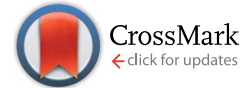

Cite this: J. Mater. Chem. A, 2015, 3 , 2883

Received 15th December 2014 Accepted 15th December 2014

DOI: $10.1039 / c 4 t a 06896 c$

www.rsc.org/MaterialsA

\section{Multiple linker half-squarylium dyes for dye- sensitized solar cells; are two linkers better than one?†}

\author{
Arthur Connell, ${ }^{a}$ Peter J. Holliman, ${ }^{\text {*a }}$ Eurig W. Jones, ${ }^{a}$ Leo Furnell, ${ }^{a}$ \\ Christopher Kershaw, ${ }^{a}$ Matthew L. Davies, ${ }^{a}$ Christopher D. Gwenin, ${ }^{a}$ \\ Mateusz B. Pitak, ${ }^{\mathrm{b}}$ Simon J. Coles ${ }^{\mathrm{b}}$ and Graeme Cooke ${ }^{\mathrm{c}}$
}

\begin{abstract}
The synthesis and full characterization of new half-squaraine dyes ( $\mathrm{Hf}-\mathrm{SQ}$ ) containing two or three carboxylate-based linker units is reported and these dyes tested in dye-sensitized solar cell (DSC) devices. The data show improved device efficiency for a Hf-SQ dye with two linkers $(\eta=5.5 \%)$ compared to the highest efficiency Hf-SQ previously reported which had only a single linker $(\eta=5.0 \%)$; this is mainly due to improved $V_{\text {oc }}$. To understand the effects of using multiple dye linker groups, device $I-V$ data have been correlated with single crystal $X$-ray structural analysis and dye electrical properties (both in solution and adsorbed to $\mathrm{TiO}_{2}$ ) using UV-visible and ATR-IR spectroscopy along with cyclic voltammetry, and also theoretical studies using density functional theory (DFT) calculations. These data show that positioning the linkers near the dye LUMO and so that this enables complete linker chemisorption are key factors for device performance.
\end{abstract}

Dye-sensitized solar cells (DSCs) are a promising form of 3rd generation photovoltaic technology. O'Regan and Grätzel's breakthrough in DSC devices used Ru bipyridyl dye N3 to sensitize nanoparticulate $\mathrm{TiO}_{2} \cdot{ }^{1}$ Since 1991 , Ru-bipy dyes have remained a widely used family of DSC dyes. ${ }^{2}$ However, these dyes are expensive which is partly due to raw material costs but also due to lengthy purification procedures which hinder scaling. They also have relatively low molar extinction coefficients $(\varepsilon)$ and generally poor spectral response above $600 \mathrm{~nm}$ leading to DSC efficiencies of $11.1 \%$ for N719 (ref. 3) and $11.4 \%$ for C101. ${ }^{4}$ Modification of the organic ligands to enhance the extinction coefficient and broaden the spectral response of $\mathrm{Ru}$ based dyes has been reported in the literature. ${ }^{5-8}$ In addition, replacement of the thiocyanate ligands has been reported which can lead to improved dye properties. These improvements include extending the spectral response and enhancing the extinction coefficient ${ }^{8}$ as well as increasing open circuit voltage and greater stability. ${ }^{9-12}$ Furthermore, modification of the bipyridyl ligands has been reported to improve the

${ }^{a}$ School of Chemistry, Bangor University, Gwynedd LL57 2UW, UK. E-mail: p.j. holliman@bangor.ac.uk; Fax:+44 (0)1248 370528; Tel: +44 (0)1248 382375

${ }^{b}$ UK National Crystallography Service, Chemistry, Faculty of Natural and Environmental Sciences, University of Southampton, Highfield Campus, Southampton, SO17 1BJ, UK

'WestCHEM, School of Chemistry, University of Glasgow, Glasgow, G12 $8 Q Q$, UK $\dagger$ Electronic supplementary information (ESI) available. CCDC 1030511-1030514. For ESI and crystallographic data in CIF or other electronic format see DOI: $10.1039 / \mathrm{c} 4 \mathrm{ta} 06896 \mathrm{c}$ hydrophobicity of Ru dyes. ${ }^{13}$ Finally, it has been reported that the purity of N3 and N719 has a profound influence on their performance as sensitizers in DSC devices. ${ }^{14}$ This has led to the development of modified bipyridyl ligands which have been used to prepare sensitizers which do not require such extensive purification during the dye synthesis. ${ }^{15}$ Whilst the aforementioned modifications of the organic ligands enable the properties of $\mathrm{Ru}$ dyes to be tuned, these dyes are still an expensive component of DSC devices because ruthenium is an expensive raw material, the synthetic procedures are multi-step and dye purification is complicated.

These issues have led to the development of "Ru-free" organic dyes (e.g. triarylamines, ${ }^{16-18}$ coumarins $^{19}$ indolines, ${ }^{20,21}$ quinoxalines ${ }^{22}$ and natural dyes ${ }^{23,24}$ ). In general, all of these dyes have been designed with a donor-pi linkeracceptor $(\mathrm{D}-\pi-\mathrm{A})$ structural arrangement ${ }^{25}$ to maximize electron injection efficiency. These organic dyes often absorb in the same region as Ru-bipy dyes $(450-600 \mathrm{~nm})$ where AM1.5 solar intensity is highest but are generally simpler to purify than Ru-bipy complexes and have significantly higher $\varepsilon$. This allows thinner photo-electrodes to be used which can reduce recombination losses and improve $V_{\mathrm{oc}}$. High $\varepsilon$ is also advantageous when co-sensitizing the $\mathrm{TiO}_{2}$ electrode to broaden spectral response because, if fewer dye sorption sites are utilized for the dye harvesting light at $400-650 \mathrm{~nm}$, this leaves more space for near infrared (NIR) dyes which absorb at $\lambda>650 \mathrm{~nm} .{ }^{26}$ Furthermore, organic dyes have surpassed $\mathrm{Ru}$ dyes with the highest $\eta$ liquid DSC reported 
$(\eta>12 \%)$ for a combination of porphyrin and triphenylamine dyes ${ }^{27}$ or a push-pull porphyrin alone. ${ }^{28}$

A relatively new organic chromophore is the half-squarylium (Hf-SQ) dye. These dyes are both synthetically versatile and are also used as an intermediate during the synthesis of unsymmetrical squaraine dyes. ${ }^{29,30} \mathrm{Hf}-\mathrm{SQ}$ dyes are known to be fluorescent $^{31}$ and early reports for ZnO-based DSC devices gave $\eta=0.27 \%$ (ref. 32) and $0.53 \%$ (ref. 33) with $\eta=3.54 \%$ (ref. 34) for $\mathrm{TiO}_{2}$ photo-electrodes. Recently, we have reported the highest efficiency Hf-SQ dyes to date $(\eta=5.0 \%) \cdot{ }^{35}$ In this report, the highest $J_{\mathrm{sc}}$ was recorded for a Hf-SQ dye with a vinyl dicyanomodified squaric acid unit which desorbed when electrolyte was added so that the resulting device gave poor $V_{\text {oc }}$ and FF. In this paper, we report a study of multiple carboxylate linkers for Hf-SQ dyes and the effects these linkers have on DSC device performance when two or three linker groups positioned around the periphery of the Hf-SQ chromophore.

\section{Results and discussion}

\section{Rationale for dye design}

The series of dyes (4), (5), (7), (8), (10) and (11) have been synthesized following our recent report of the highest efficiency Hf-SQ DSC device $(\eta=5.0 \%) .^{35}$ In the previous report, we studied the influence of the linker position on device performance. Interestingly, the highest $J_{\mathrm{sc}}$ was observed for a dye with vinyl dicyano-modified squaric acid unit; labelled compound (8) in paper; ${ }^{35}$ here this dye will be labelled ( $\left.\mathbf{8}^{\prime}\right)$ (Fig. 1). However, the overall device efficiency was limited because $\left(\mathbf{8}^{\prime}\right)$ appeared to desorb when electrolyte was added resulting in poor $V_{\text {oc }}$ and FF. Here, we have studied the desorption process further by pumping electrolyte through the cavity of DSC device dyed with

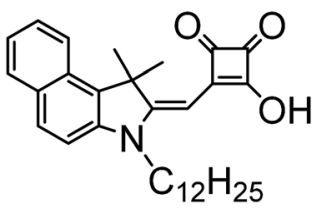

(7')

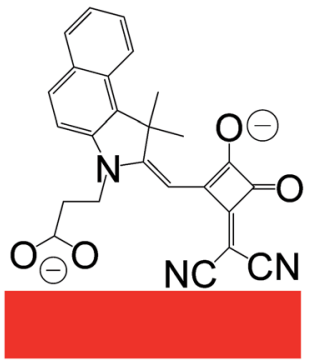

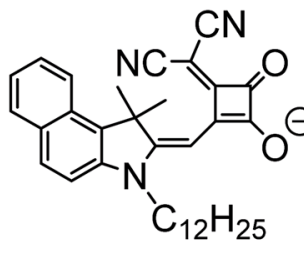

(8')

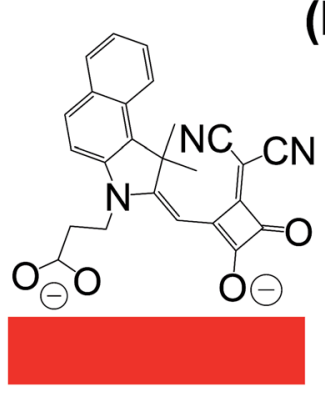

(8)

Fig. 1 (a) Molecular structures of $\left(7^{\prime}\right)$ and $\left(8^{\prime}\right)$ from ${ }^{35}$ and (b) possible binding modes of (8) from this work. $\left(8^{\prime}\right)$ and the data show that dye is desorbed by this (Fig. 2). The approach tested in this paper has been to synthesise Hf-SQ dyes which are related to the highly efficient dyes in $^{35}$ but with more than one carboxylate linker to test if this enables the dyes to adsorb more strongly to $\mathrm{TiO}_{2}$ and to study how this affects device performance. For example, $(\mathbf{4})$ is an analogous dye to $\left(\mathbf{8}^{\prime}\right)$ but with a second carboxylate linker attached to the $\mathrm{N}$ of the indole. To test the effect of having 2 linkers on dye desorption, a $\mathrm{TiO}_{2}$ electrode was dyed with (4) and then electrolyte was pumped through the device cavity (Fig. 2b). This shows that dye desorption does not occur for (4). Instead the dye remains bonded to the surface and no discolouration is observed. By comparison, (5) is similar to (4) but without vinyl dicyano modification of the squaric acid unit. Hence, for both (4) and (5) the two linker groups are at the same end of the dye. To compare with this, dye (8) was designed with carboxylate linkers at opposite ends of the molecule and (11) with 3 carboxylate linkers; on the $\mathrm{N}$ atom and benzene of the indole and through the squaric acid unit. Dyes (7) and (10) are related to (8) and (11), respectively but without vinyl dicyano modification of the squaric acid unit.
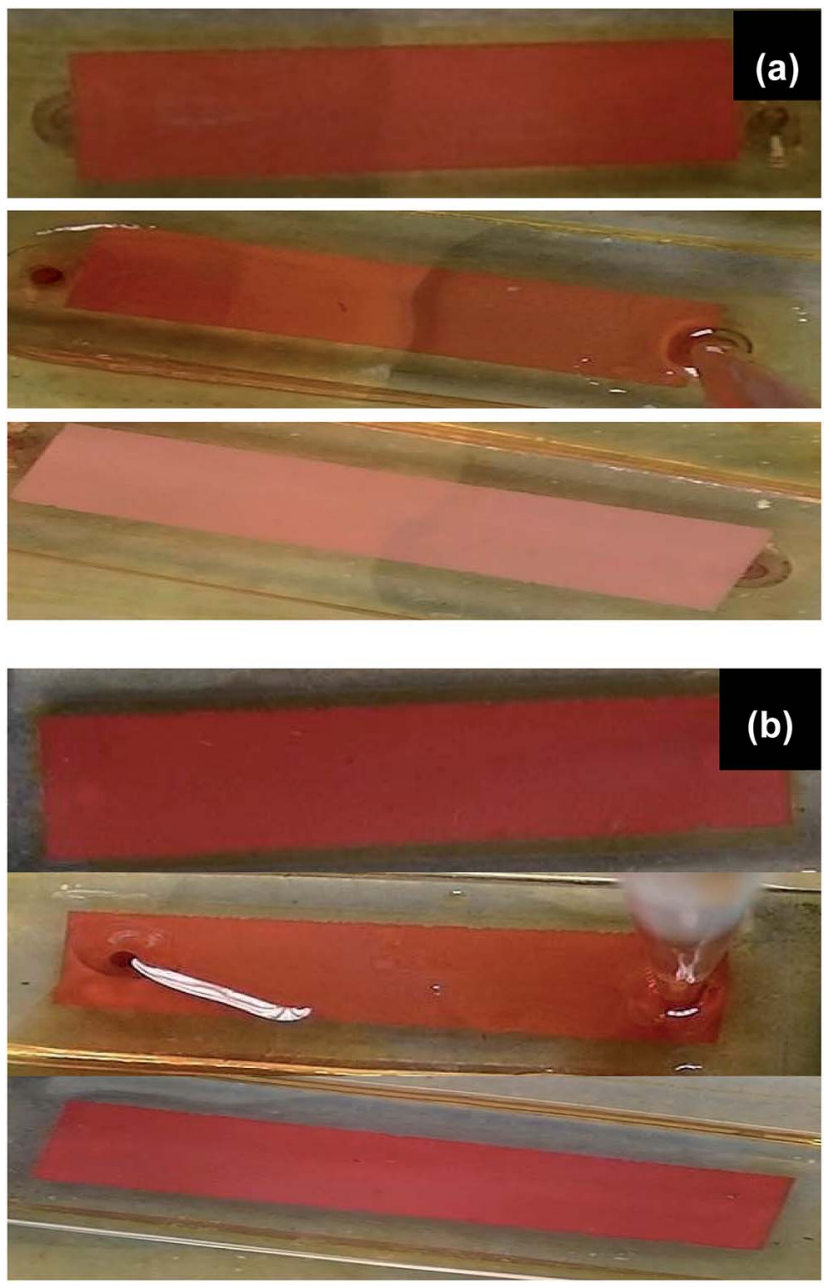

Fig. 2 (a) Desorption of $\left(\mathbf{8}^{\prime}\right)$ from ${ }^{35}$ during acetonitrile electrolyte infusion showing (top) dyed film, (middle) during and (bottom) after electrolyte addition and (b) the equivalent data for (4) from this paper. 


\section{Dye synthesis}

The synthetic routes used to produce the Hf-SQ used in this work are shown in Scheme 1(a-c). The first step is the esterification of squaric acid in ethanol to give (1) which was prepared according to the method described by Terpetschnig et al. in good yield with spectroscopic data in line with the literature. ${ }^{36}$ Compounds (2) and (3) have been reported in our previous work. $^{35}$ To the best of our knowledge (4-11) have not been reported in the literature and were identified using several analytical techniques. The resonances identified in the ${ }^{1} \mathrm{H}$ NMR spectrum suggest that (4) has been isolated as the triethylamine salt. Six protons are identified in the aromatic region between 8.10 and $7.41 \mathrm{ppm}$ with multiplicities including a doublet and multiplets. Resonances at 7.32, 4.25, 2.80 and 1.93 ppm have the correct multiplicities and integration to be identified as the methylene proton located near the squaric acid moiety, the ethyl group attached to the nitrogen of the indole and the methyl groups located at the 3 position of the indole unit, respectively. The quintet and triplet at 3.24 and $1.33 \mathrm{ppm}$, which integrate to six and nine protons respectively, are caused by the ethyl group of the triethylamine cation. Furthermore, the coupling constants calculated for the protons in each environment are similar to those reported for the previous half squaraine dyes. ${ }^{35}{ }^{13} \mathrm{C}$ NMR has a resonance at $112 \mathrm{ppm}$ which is associated with the nitrile functional group. In addition, resonances for the carbonyl group of the squaric acid and carboxylic acid moiety are also identified between 191 and 173 ppm. The ethyl group of the triethylamine cation can be identified between 38.39 and 7.93 ppm. Analysis using high resolution mass spectrometry identifies the $\mathrm{M}^{+}$ion at 424.1294 which corresponds to the target molecule in the non-salted form. In addition, an isotope profile is detected which fits the theoretical isotope profile expected for this molecule. Attenuated total reflectance infrared (ATR-IR) spectroscopy has been used to identify functional groups in the molecule including the nitrile and carbonyl groups at 2178, 1732 (s), 1626 (s), 1595 (s), 1537 (s), $1517(\mathrm{~s}) \mathrm{cm}^{-1}$, respectively. (4) was isolated in 75\% yield and has a melting point between $175-179{ }^{\circ} \mathrm{C}$, which is similar to a vinyl dicyano half squaraine reported in our previous work. ${ }^{35}$ Finally, the structure of (4) was confirmed from single crystal X-ray crystallography and is show in Fig. 3. The crystal structure of (4) shows the expected molecular configuration with a propionic acid linker attached to the indole $\mathrm{N}$ and a second carboxylate linker being the squaric acid moiety. The crystal structure also confirms that the squaric acid unit has been modified by the addition of a vinyl dicyano group but interestingly that this group lies on the same side of the molecule to the propionic acid linker. Finally, this crystal structure also shows the presence of a triethylamine counterion as suggested by the NMR data. As expected, this is located closest to the oxygen atoms of the modified squaric acid unit where the carboxylate anionic charge is found.

Compounds (5-11) were isolated in good yield and analysed using the same techniques used to identify (4). Focussing on the major differences between these molecules, (5) is essentially the same as (4) but without a vinyl dicyano group on the squaric

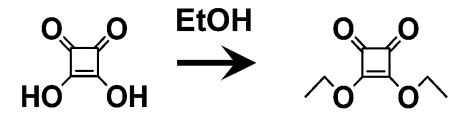

(a)

(1)
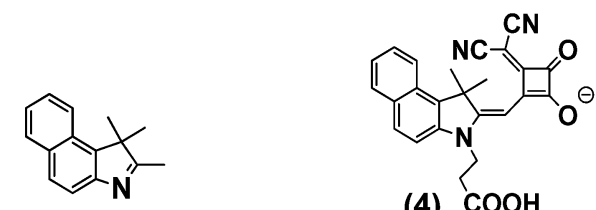<smiles>CC(C)(C)CCC(=O)O</smiles>

(4)
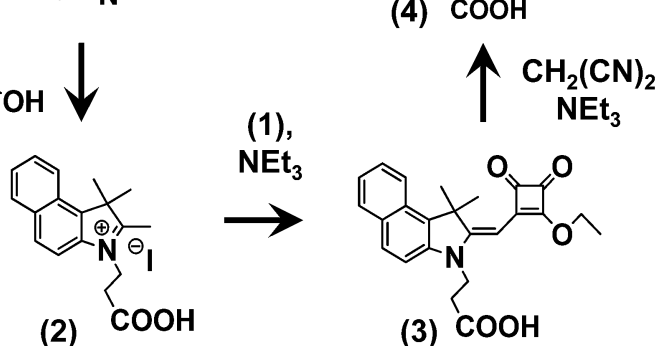

(3) $\mathrm{COOH}$

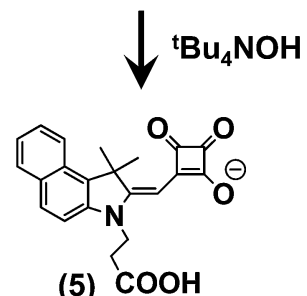

(5) $\mathrm{COOH}$

(b)
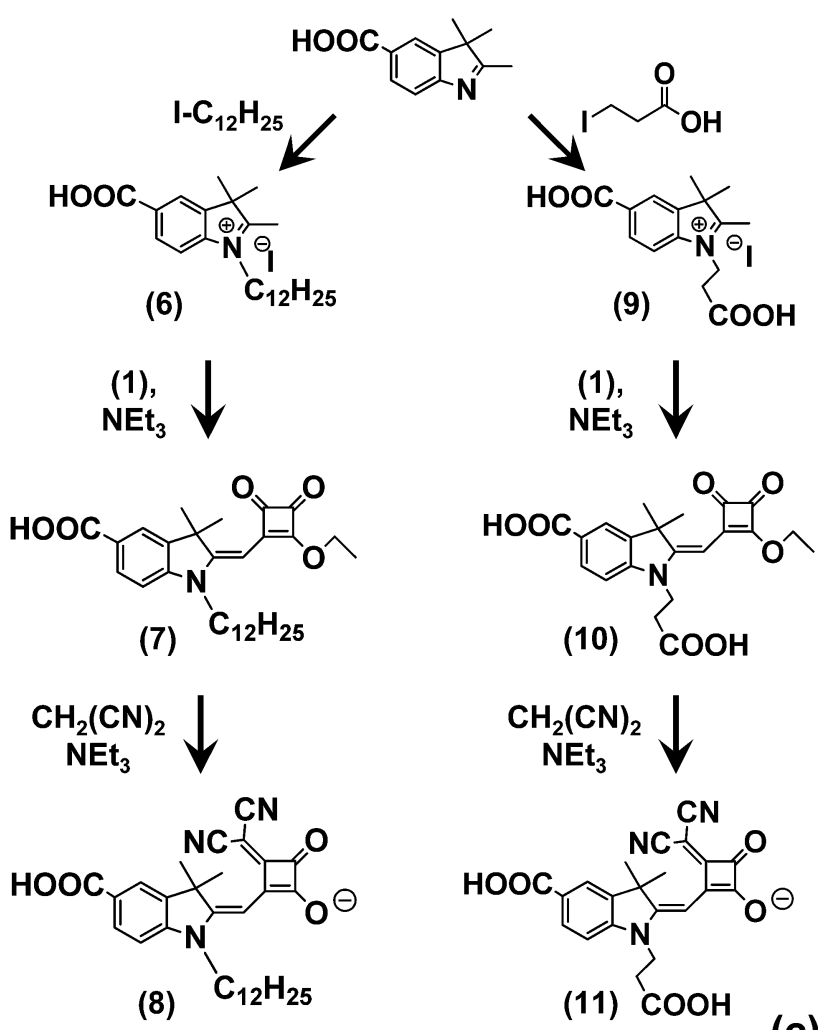

(c)

Scheme 1 Synthetic pathways to multiple linker half-squaraine dyes. 


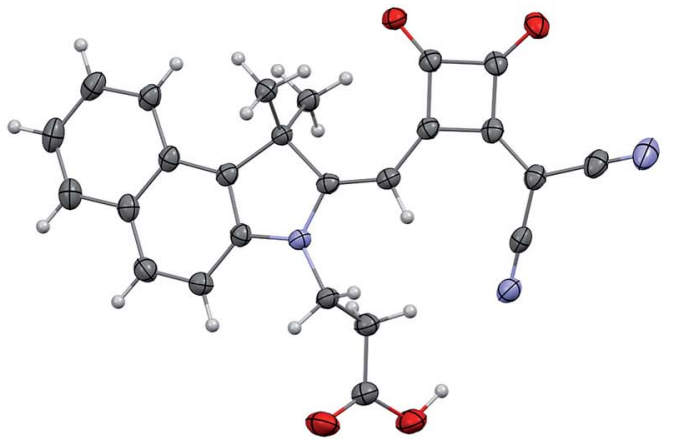

(a)

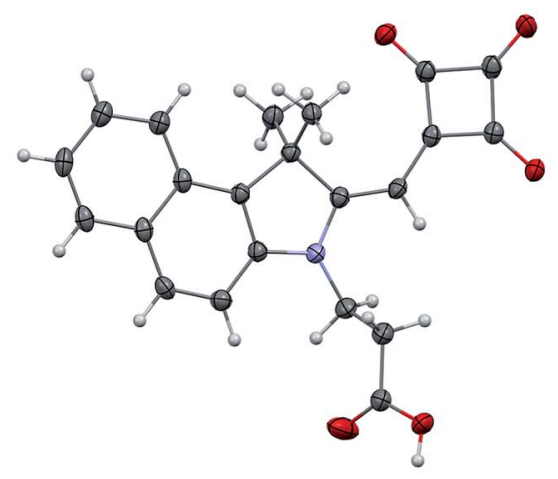

(b)

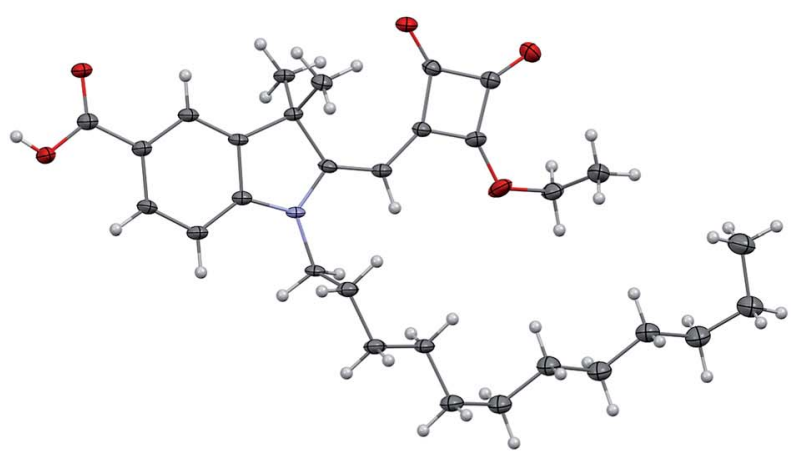

(c)

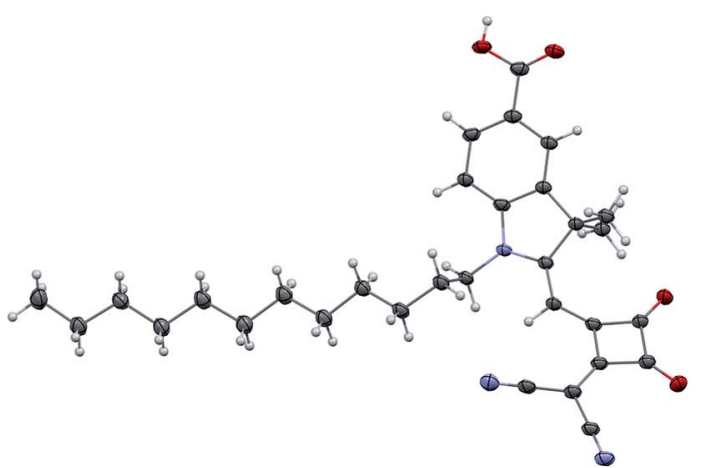

(d)

Fig. 3 X-ray crystal structures of (a) (4), (b) (5), (c) (7) and (d) (8) (polymorph 1). Displacement ellipsoids - 50\% probability. For clarity counteranions as well as molecular disorder components have been omitted for (4), (5) and (8) (polymorph 1). Asymmetric part of the unit cell of $(7)$ contains two independent molecules $\left(Z^{\prime}=2\right)$. Only one has been shown. acid unit. The ${ }^{13} \mathrm{C}$ NMR and ATR data confirm the absence of nitrile groups in (5) through the absence of signals at $112 \mathrm{ppm}$ and $2178 \mathrm{~cm}^{-1}$, respectively. The other NMR and ATR data are similar to (4) as expected and mass spectrometry also confirms (5) with $\mathrm{M}^{+}$at 270.1126. Single crystal X-ray crystallography also shows the expected molecular structure of (5) and it does mirror the structure of (4) as expected but without the vinyl dicyano modification to the squaric acid group.

The synthesis of (8) begins with alkylation of a carboxylate indole to produce (6) which is confirmed by mass spectrometry $\left(\mathrm{M}^{+}=372.887\right)$. This was converted to the half squaraine dye $(7)$ by reaction with (1) as evidenced by the additional peaks between 0.95 and $1.71 \mathrm{ppm}$ for the alkyl chains on the indole nitrogen and in the ${ }^{1} \mathrm{H}$ NMR and 3 signals for $\mathrm{C}=\mathrm{O}$ between 185 and $190 \mathrm{ppm}$. (7) was also confirmed by mass spectrometry $\left(\mathrm{M}^{+}=494.2929\right)$. Single crystal X-ray crystallography (Fig. 3) verifies the molecular structure of (7) with a carboxylate linker attached to the benzene ring of the indole and an ester group attached to the squaraine moiety. In the context of this study, this is important because it means that (7) can only link to $\mathrm{TiO}_{2}$ through a single carboxylate linker.

The squaraine ester of (7) is then de-esterified and a vinyl dicyano group added by reaction with $\mathrm{CH}_{2}(\mathrm{CN})_{2}$ to produce (8). This is confirmed by additional signals for nitrile at 117-118 ppm in the ${ }^{13} \mathrm{C}$ NMR and at $2182 \mathrm{~cm}^{-1}$ in the infrared data. Single crystal X-ray crystallography again proves the expected structure (Fig. 3d). Importantly, the data show the presence of two potential linker groups for this dye. These are the carboxylate linker on the benzene ring of the indole and the vinyl dicyano-modified squaric acid unit. These are oriented on one side of the molecule in the solid state which suggests it might be possible for both linkers to adsorb to $\mathrm{TiO}_{2}$ at the same time. Interestingly, we have found that (8) also crystallises into a second polymorph; (8) (polymorph 2) (see ESI†). This varies from (8) (polymorph 1) shown in Fig. 3 mainly through the $\mathrm{H}$-bonding which influences the both the crystal packing and the relative positions of the Hf-SQ anions and triethylamine cations.

In the first step towards the synthesis of (11), a propionic group is first added to the $\mathrm{N}$ atom of a carboxy indole to make (9) which is confirmed by mass spectrometry $\left(\mathrm{M}^{+}=276.1227\right)$. This is then converted to the half-squaraine (10) which is evidenced by the ${ }^{1} \mathrm{H}$ NMR signals at between 3.2 and $4.4 \mathrm{ppm}$ for the $\mathrm{C}-\mathrm{H}$ of the propionic acid and squaraine ester groups, the $\mathrm{C}=\mathrm{O}$ signals at $190-200 \mathrm{ppm}$ in the ${ }^{13} \mathrm{C}$ NMR and the mass spectrometry $\left(\mathrm{M}^{+}=398.1235\right)$. This molecular structure of $(\mathbf{1 0})$ is important for this study because the molecule contains two potential carboxylate linkers attached to the benzene ring and the $\mathrm{N}$ atom of the indole, respectively. The final dye (11) is produced from (10) by simultaneous modification and deesterification of the squaraine ester to produce the vinyl dicyano modified half-squaraine. The production of (11) is confirmed by the additional nitrile signals in the ${ }^{13} \mathrm{C}$ NMR between 117-119 ppm and in the IR at $2198 \mathrm{~cm}^{-1}$ and the mass spectrometry $\left(\mathrm{M}^{+}=418.1036\right)$. This molecule is important for this study because it contains 3 potential carboxylate linkers; the squaric 
acid moiety in addition to carboxylates on the benzene ring and $\mathrm{N}$ atom of the indole.

\section{Spectroscopic analysis}

Fig. 4 shows UV-vis spectra of dyes in solution and after sorption onto $\mathrm{TiO}_{2}$ photo-electrodes. The spectra in solution (Fig. 4a) show that modification of the central squaric acid moiety by replacing a carbonyl group with a vinyl dicyano group causes red shifts in the spectra of (4), (8) and (11) by comparison to the unmodified dyes (5), (7) and (10), respectively. In addition, the highest molar extinction coefficient $(\varepsilon)$ is observed for the esterified squaraine (7) with generally higher $\varepsilon$ for vinyl dicyano modified dyes apart from (11) which has the lowest $\varepsilon$ of all the dyes synthesized. The spectra obtained for (4) and (5) are similar to dyes $\left(7 \mathbf{b}^{\prime}\right)$ and $\left(\mathbf{8}^{\prime}\right)$ reported in our previous work. ${ }^{35}$ This is interesting because the main structural difference associated with the new dyes reported in this paper is the addition of a propionic acid linker group to the $\mathrm{N}$ of the indole. This suggests that this new group plays little role in the HOMO or LUMO of these dyes in solution. In turn, this suggests that the main role of these additional groups is predominantly as linkers onto $\mathrm{TiO}_{2}$.

Fig. $4 \mathrm{~b}$ shows the transmission UV-vis data when the dyes are adsorbed onto transparent, mesoporous titania films. The data show that the absorption is broadened as might be expected for molecules which are chemisorbed on a surface. Interestingly, as
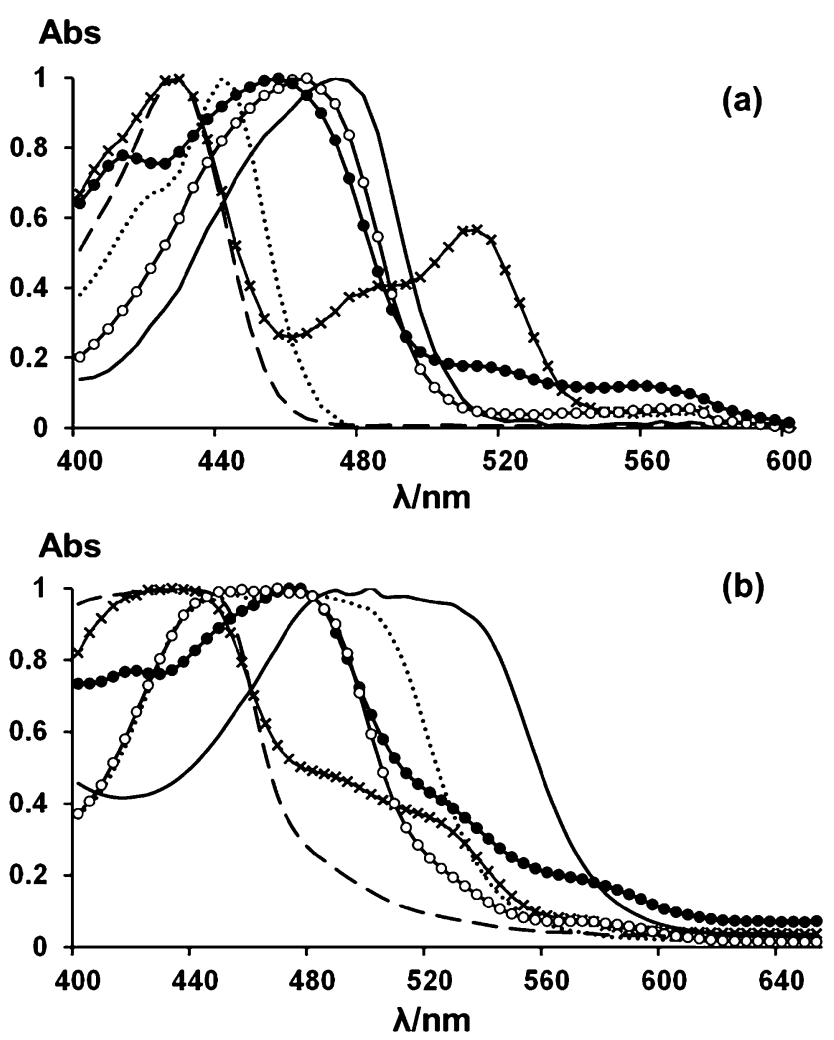

Fig. 4 UV-vis spectra of selected dyes (a) in solution $(1 \mu \mathrm{M})$ and (b) adsorbed to $\mathrm{TiO}_{2}$ films; (4) solid line, (5) dotted line, (7) long dashes, (8) open circles, (10) crosses, (11) filled circles. for the solution data, the spectra for adsorbed (4) and (5) are similar to $\left(\mathbf{7 \mathbf { b } ^ { \prime } )}\right.$ and $\left(\mathbf{8}^{\prime}\right)$ reported previously. ${ }^{35}$ This supports the notion that, because the additional propionic linkers of (4) and (5) are attached to the indole $\mathrm{N}$ atom, they only act as additional linkers to the $\mathrm{TiO}_{2}$ surface and that they do not contribute to the HOMO or LUMO of the adsorbed dyes. This is important because $\left(7 \mathbf{b}^{\prime}\right)$ from ${ }^{35}$ can only chemisorb to $\mathrm{TiO}_{2}$ through covalent ester bonds between the squaric acid moiety and surface hydroxyls whilst the adsorption mode of and $\left(\mathbf{8}^{\prime}\right)$ is less clear. By comparison, (4) and (5) can chemisorb both through the squaric acid and/or from the propionic acid linker. Fig. 2 illustrates our observations that (5) adsorbs much more strongly to $\mathrm{TiO}_{2}$ than $\left(\mathbf{8}^{\prime}\right)$ producing stable devices that can easily be measured over periods of days. By comparison, devices made from $\left(\mathbf{8}^{\prime}\right)$ last minutes at most. Hence, we can assume that (4) does attach to the $\mathrm{TiO}_{2}$ surface via the propionic linker group because the dye is not desorbed upon infusion of electrolyte into the cell. In addition, because the UV-vis spectra is similar to $\left(\mathbf{8}^{\prime}\right),{ }^{35}$ this suggests that the vinyl dicyano-modified squaric acid moiety may also interact with the $\mathrm{TiO}_{2}$. For (5), one could argue that this can attach to the surface via either the central squaric acid moiety and/or from the carboxylic acid linker attached to the nitrogen of the indole. Given that our previous observations $\mathrm{s}^{35}$ are that unmodified squaric acid interacts strongly with $\mathrm{TiO}_{2}$, it seems most likely that (5) may bonds to $\mathrm{TiO}_{2}$ in a similar orientation to (4); i.e. that both the squaric and propionic acid units are involved. In further support of this assertion, the UV-vis spectrum for (5) is similar to those of $\left(7 \mathbf{b}^{\prime}\right)$ and $\left(\mathbf{1 0}^{\prime}\right)$ reported in our previous work ${ }^{35}$ because (7) can only attach through the squaric acid unit and $\left(\mathbf{1 0}^{\prime}\right)$ can only attach through the indole propionate because it's squaraine unit is esterified.

To further study how Hf-SQ dyes adsorb on $\mathrm{TiO}_{2}$, new Hf-SQ dyes were prepared with an esterified squaraine moiety to prevent this bonding to the surface. In addition, the carboxylate linker was positioned on the benzene ring of the indole so that the squaraine ester should be orientated away from the $\mathrm{TiO}_{2}$ surface. For the first example, (7), the UV-vis spectrum of $\mathrm{TiO}_{2^{-}}$ sorbed (7) exhibits a smaller bathochromic shift relative to solvated (7) than that observed for dyes where it is believed that the squaric acid unit can interact with the surface. These dyes include $\left(\mathbf{7} \mathbf{b}^{\prime}\right),\left(\mathbf{8}^{\prime}\right)$ and $\left(\mathbf{1 0}^{\prime}\right)$ from, ${ }^{35}$ and (4) and (5) reported here. By comparison, when (7) is modified to form the vinyl dicyano analogue (8), this also de-esterifies the squaric acid unit which would be expected to enable dye- $\mathrm{TiO}_{2}$ chemisorption through the squaraine moiety. In line with this assertion, a larger bathochromic shift is observed for (8) which is in line with other vinyl dicyano modified dyes (60 to $80 \mathrm{~nm}$ ). Whilst the UV-vis data cannot prove the orientation of the dyes on the $\mathrm{TiO}_{2}$ surface, these data do suggest that larger bathochromic shifts are observed for sorbed dyes when adsorbed through the squaraine moiety and that (8) may bind preferentially through the vinyl dicyano-modified squaraine compared to the indole benzene carboxylate. The peak broadening and red-shifts observed when the dyes chemisorb to $\mathrm{TiO}_{2}$ are common in DSC dyes and has been observed previously for Hf-SQ dyes. ${ }^{33,35}$ To rationalise this, Cicero et al. used DFT and related the phenomena to the formation of ester bonds between squaric 
acid oxygen and surface metal atoms which lowers the HOMOLUMO gap. Interestingly, whilst these workers found that the HOMO changes little on sorption, they reported that the LUMO of the $\mathrm{TiO}_{2}$-dye system does shift. They also suggested that electron excitation into the new LUMO, which includes character from the $\mathrm{O}$ and $\mathrm{C} 2 \mathrm{p}$ orbitals of the squaric acid moiety and surface $\mathrm{Ti} 3 \mathrm{~d}$ orbitals, should enhance electron injection from the dye into the $\mathrm{TiO}_{2}$.

The next dye (10) was designed with an esterified squaraine and two carboxylate linkers; on the benzene ring and the $\mathrm{N}$ of the indole. The UV-vis spectrum of solvated (10) shows three absorption bands; at $420 \mathrm{~nm}$ and weaker bands at 480 and $515 \mathrm{~nm}$. For $\mathrm{TiO}_{2}$-adsorbed (10), these bands all broaden considerably. Whilst this makes precise assignment of peak positions difficult, there is little evidence of any major shifts on these peaks and certainly not to the extent observed for the squaraine-bonding dyes. In line with our previous data, modification of (10) to form the de-esterified vinyl dicyano squaraine analogue (11) does show a bathochromic shift for the adsorbed versus solvated data. This is interesting because (11) has three potential carboxylate linkers; on the benzene ring and $\mathrm{N}$ atom of the indole and through the modified squaraine unit. Whilst these data do not rule out some interaction through the first two linkers, they do suggest that that the modified squaraine moiety does interact with the $\mathrm{TiO}_{2}$ surface.

To further investigate dye- $\mathrm{TiO}_{2}$ interactions, ATR-infrared spectroscopy has been used to compare adsorbed dye and dye powders (see ESI $\dagger$ ). Firstly, the molecular structure of dyes (4) and (5) should make it possible for these dyes to covalently link to $\mathrm{TiO}_{2}$ through two carboxylate linker groups; the squaraine moiety and the propionic acid on the indole N. For (4), the sharp, intense carbonyl $\left(1650 \mathrm{~cm}^{-1}\right)$ and nitrile $\left(2225 \mathrm{~cm}^{-1}\right)$ peaks in the powder broaden and shift in frequency (to 2000$2100 \mathrm{~cm}^{-1}$ for nitrile). The shift in the nitrile peak suggests an interaction with the $\mathrm{TiO}_{2}$ surface which, although it cannot clarify any surface interaction from the propionic acid, does suggest that (4) may interact with $\mathrm{TiO}_{2}$ through the nitrile groups of the vinyl dicyano-modified squaraine unit. For (5), which has no nitrile groups, the data for the dyed film show a broadening and downward shift of the sharp carbonyl signal of the powder. This dye can only chemisorb through carboxylate linkers but the broadness of the sorbed carbonyl signals does not allow any differentiation between sorption modes. This may be due to the poor resolution of the peaks or it may reflect a mixture of surface binding modes (e.g. mono- and bi-dentate). Interestingly, the spectra for (4) and (5) show much greater carbonyl peak shifts between neat powder and $\mathrm{TiO}_{2}$-sorbed dyes than the single linker dyes reported previously ${ }^{35}$ (see ESI $\dagger$ ); thus, $\left(7 \mathbf{b}^{\prime}\right)$ or $\left(\mathbf{8}^{\prime}\right)$ can only bond to the surface from the squaraine unit and $\left(\mathbf{1 0}^{\prime}\right)$ which can only link to $\mathrm{TiO}_{2}$ via an indole $\mathrm{N}$ linker. For instance, the carbonyl signals of $\left(7 \mathbf{b}^{\prime}\right)$ and nitrile and carbonyl peaks of $\left(\mathbf{8}^{\prime}\right)$ do broaden on sorption to $\mathrm{TiO}_{2}$ but only shift $c a$. $10 \mathrm{~cm}^{-1}$ in frequency. These data suggest that, for dyes (4) and (5) which contain both propionic and squaric acid groups, both are involved in surface binding to $\mathrm{TiO}_{2}$.

By comparison with (4) and (5), dye (7) possesses only one carboxylate linker which is located on the benzene ring of the indole. The ATR-IR data show that, although there is a broadening of the peaks for the $\mathrm{TiO}_{2}$-sorbed (7) compared to the neat powder (ESI Fig. $4 \dagger$ ), the carbonyl peaks do not shift although there is a significant reduction in the $\mathrm{O}-\mathrm{H}$ signal $\left(>3000 \mathrm{~cm}^{-1}\right)$ on sorption. This presumably reflects the formation of an ester linkage between the carboxylate group and the $\mathrm{TiO}_{2}$ surface. A similar scenario is observed for (8) with a reduction in the $\mathrm{O}-\mathrm{H}$ signal, and a slight broadening but very little shift on the nitrile and carbonyl peaks. This suggests that bigger peak shifts are observed when the dye sorbs to $\mathrm{TiO}_{2}$ through linker groups which are more associated with increased electron density of the LUMO. ${ }^{35}$ In support of this assertion, dye (10) shows two carbonyl signals in the powder which corresponds to the two linkers in the structure. These broaden and shift very slightly to lower frequency on sorption which is in line with the molecule sorbing to $\mathrm{TiO}_{2}$ at the opposite end to the squaraine moiety. By comparison, (11) is interesting because it possesses 3 linker groups and the position of these groups around the outside of the molecule suggest it would be difficult for all 3 linkers to chemisorb to $\mathrm{TiO}_{2}$ simultaneously (Scheme 1). In this context, the absence of a significant shift in the nitrile signal (ESI Fig. $7 \dagger$ ) suggests that this dye does not appear to sorb strongly through the squaraine unit but rather through the other carboxylate linkers.

\section{Device testing}

Table 1 shows $I-V$ data for Hf-SQ devices with and without $5 \mathrm{mM}$ chenodeoxycholic acid (CDCA). As stated above, one aim when designing these Hf-SQ dyes was to retain the optical properties of $\left(\mathbf{8}^{\prime}\right)$ from our previous work ${ }^{35}$ but to modify the molecular structure to enable the new dye to bind more strongly to a $\mathrm{TiO}_{2}$ electrode so that it might remain bonded after the addition of electrolyte solution.

Thus, dye (4) was designed and synthesized with a vinyl dicyano modified squaric acid unit but with a second carboxylate linker attached the indole $\mathrm{N}$. The power conversion efficiency $(\eta)$ of devices made using (4) is $4.7 \%$ and $4.5 \%$, with and without CDCA, respectively. By comparison, the previous dye

Table 1 I-V for devices prepared using Hf-SQ dyes ( $\eta$ data are the mean of 5 replicates with standard error $\pm 0.2 \%$ )

\begin{tabular}{llllc}
\hline Dye & $\eta / \%$ & FF & $V_{\text {oc }} / \mathrm{V}$ & $J_{\mathrm{sc}} / \mathrm{mA} \mathrm{cm}^{-2}$ \\
\hline$(4)$ & 4.5 & 0.69 & 0.67 & 9.80 \\
$(\mathbf{4})+$ CDCA & 4.7 & 0.69 & 0.68 & 10.00 \\
$(5)$ & 5.4 & 0.69 & 0.72 & 10.80 \\
$(5)+$ CDCA & 5.5 & 0.66 & 0.79 & 10.50 \\
$(7)$ & 2.1 & 0.66 & 0.64 & 5.20 \\
$(7)+$ CDCA & 2.9 & 0.64 & 0.71 & 6.12 \\
$(8)$ & 3.1 & 0.78 & 0.69 & 5.68 \\
$(8)+$ CDCA & 3.1 & 0.76 & 0.68 & 6.10 \\
$(\mathbf{1 0})$ & 2.8 & 0.71 & 0.66 & 5.39 \\
$(\mathbf{1 0})+$ CDCA & 2.9 & 0.69 & 0.63 & 6.76 \\
$(\mathbf{1 1})$ & 2.8 & 0.68 & 0.59 & 7.10 \\
$(\mathbf{1 1})+$ CDCA & 3.0 & 0.71 & 0.64 & 6.57 \\
N719 only & 6.4 & 0.60 & 0.73 & 14.69
\end{tabular}


$\left(\mathbf{8}^{\prime}\right)$ gave $\eta=2.8 \%$ as a result of a lower fill factor (FF) and open circuit voltage $\left(V_{\mathrm{oc}}\right)$ which was ascribed to rapid dye desorption in liquid electrolyte during measurement. The data for (4) show much higher $V_{\mathrm{oc}}$ and $\mathrm{FF}$ and the stability of the device measurements confirm that the two linker approach has been successful.

However, in this study, the highest performing dye was actually (5) which gives $\eta=5.5 \%$. This dye actually performs slightly better than $\left(7 \mathbf{b}^{\prime}\right)$ from our recent report ${ }^{35}$ which gave $\eta=$ $5.0 \%$ and, at that time, was the most efficient Hf-SQ dye. Thus, (5) is currently the most efficient Hf-SQ dye mainly due to an increase in $V_{\text {oc }}$ which here is $0.79 \mathrm{~V}$ compared to $0.71 \mathrm{~V}$ in the presence of CDCA. This is further evidence that attaching the Hf-SQ dyes to the surface from two anchoring points is advantageous to device performance. However, for dyes which can link to the surface from a carboxylic acid attached to the benzene ring of the indole an increase of $V_{\mathrm{oc}}$ was not observed when an additional linker group was added to the nitrogen of the indole. For example, dyes (7) and (8) gave devices with $V_{\mathrm{oc}}$ of 0.71 and $0.68 \mathrm{~V}$, respectively. By comparison, (10) and (11) also have a carboxylic acid linker which is attached to the nitrogen of the indole but the $V_{\mathrm{oc}}$ is lower i.e. 0.63 and $0.64 \mathrm{~V}$, respectively. In addition, modification of the central unit to a vinyl dicyano group results in a lower $V_{\text {oc }}$ in analogous dyes and a comparable $J_{\text {sc }}$, despite a broadening of the spectral response. This, allied to the ATR-IR data, suggests that the close proximity of the vinyl dicyano unit to the squaric acid linker may have a negative influence on electron injection and/or dye regeneration processes.

The spectral response of the dyes has also been tested (Fig. 5) and the data show that dye (4) responds most strongly (EQE ca. $60 \%$ ) between 500 and $575 \mathrm{~nm}$ which is where solar intensity is highest. This correlates with this dye having good efficiency $(\eta=$ $4.7 \%$ ) and also the vinyl dicyano modification of the squaraine unit which re-shifts the light harvesting relative to (5). Thus, by comparison, the spectral response of (5) is highest between

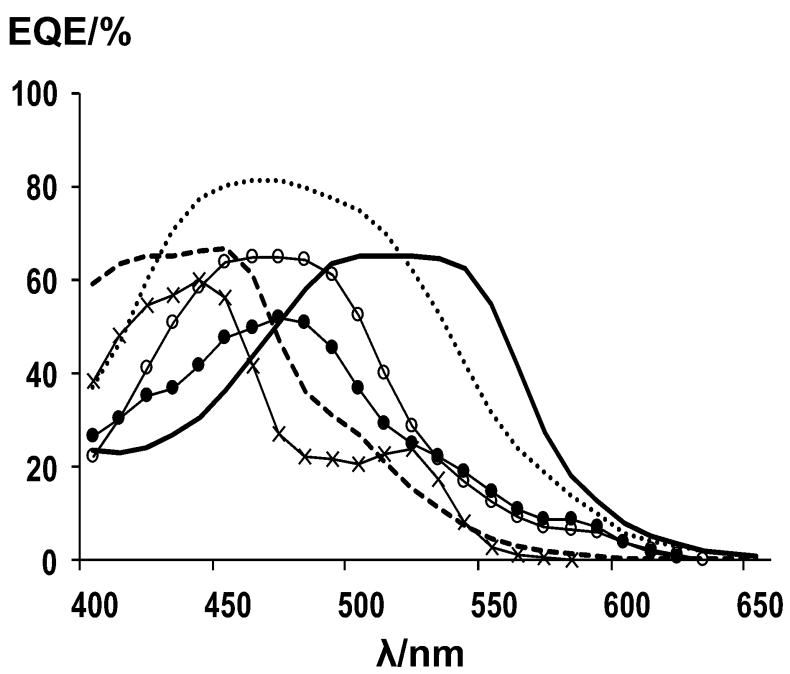

Fig. 5 EQE data of DSC devices using; (4) solid line, (5) dotted line, (7) long dashes, (8) open circles, (10) crosses, (11) filled circles.
430 and $540 \mathrm{~nm}$. However, the EQE of (5) is significantly higher ca. $80 \%$ which is reflected in the higher efficiency of (5) with $\eta=$ $5.5 \%$. The spectral response data are very much in line with the DRUV data of the adsorbed dyes (Fig. 4b) and also with the $\varepsilon$ measured for dissolved dyes which are $47000 \mathrm{M}^{-1} \mathrm{~cm}^{-1}$ for (4) and $18400 \mathrm{M}^{-1} \mathrm{~cm}^{-1}$ for (5) suggesting that, for devices with similar $\mathrm{TiO}_{2}$ films and electrolyte, light harvesting most strongly influences EQE and device performance. A similar pattern is observed for the other dyes tested in that the EQE of (7), (8), (10) and (11) all strongly resemble the DRUV of the adsorbed dyes (Fig. 4b). Thus, as expected, the EQE of dyes (8) and (11) are redshifted relative to (7) or (10) due to the presence of the vinyl dicyano modifications of the squaraine unit. However, the solution $\varepsilon$ of these dyes seems less important as all four dyes have very similar device efficiencies ( $\eta$ is $c a$. 3.0\%) whilst $\varepsilon$ varies from 2500 to $78000 \mathrm{M}^{-1} \mathrm{~cm}^{-1}$.

\section{HOMO-LUMO characteristics}

Cyclic voltammetry (CV) measurements of selected dyes $(10 \mathrm{mM})$ have been carried out in degassed DMF to compare dye oxidation and reduction processes with spectral and DSC device data along with theoretical DFT calculations to try to further examine any structure-activity relationships arising from changes to the dye linker position.

As an example, the CV data for (10) are shown in Fig. 6 with the onsets of the oxidation and reduction peaks which have been used to calculate the dye band gap labelled. Furthermore, the CV data show no changes following ten cycles scanned at a rate of $50 \mathrm{mV} \mathrm{s}^{-1}$. However, the reduction signals for all the dyes tested are very broad (see ESI Fig. 11-19†). To clarify the reduction voltages, each dye was held at $2.0 \mathrm{~V}$ for $60 \mathrm{~s}$ to oxidise all the dye molecules in solution. By doing this, the shape of the reduction peak changed and a more defined peak was obtained. By using these peaks to calculate the band gap of the dyes, good correlations with the bang gaps calculated using the UV-vis onsets of the dyes in solution were obtained (Table 2). In addition, the UV-vis data (Fig. 4) have shown that modification of the central squaric acid moiety to a vinyl dicyano group

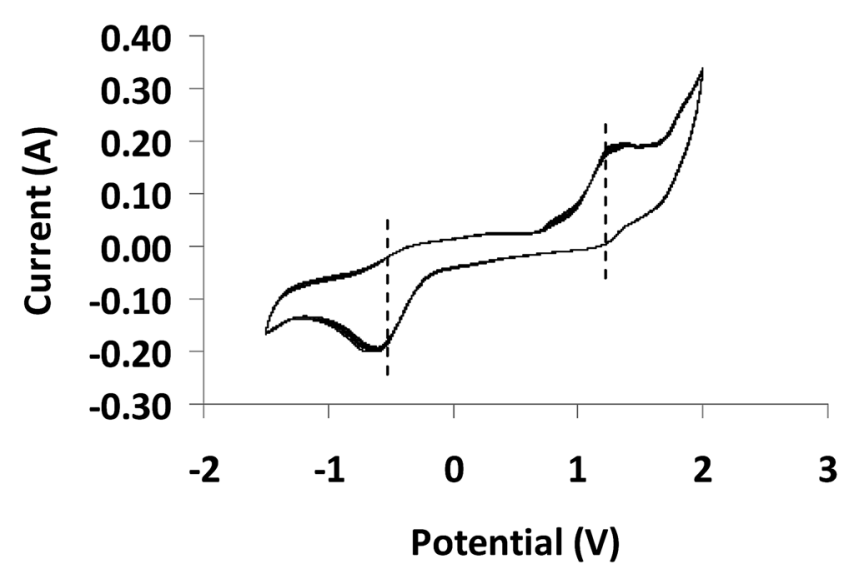

Fig. 6 Cyclic Voltammetry of (10) $10 \mathrm{mM}$ in degassed DMF vs. Ag/ $\mathrm{AgCl}$. 
resulted in a bathochromic shift in solution when the dye attaches to a titania surface compared to in solution (e.g. for dyes (4), (8) and (11)). This resulted in a decrease of the dye band gap when calculated from the absorption onset which was also observed in the CV data (Table 2). For example, shifts in the anodic and cathodic waves were observed for (4), (8) and (11) by comparison to (5), (7) and (10), respectively. In addition, both the onset and mid-wave $\mathrm{CV}$ data have been used to calculate HOMO-LUMO potentials and band gaps versus the NHE. As expected, the band gap energies obtained from onset $\mathrm{CV}$ data correlate with the onset of the absorption measured from the solution UV-visible spectroscopy whilst the mid-wave CV values correlate well with the DFT calculations. Furthermore, the CV data (Fig. 6 and Table 2) suggest that the LUMO levels of the dyes reported here should be above the conduction band of $\mathrm{TiO}_{2}$ to facilitate successful electron injection from the dye into the $\mathrm{TiO}_{2}$.

In order to compare the band gaps calculated from the HOMO-LUMO levels (Table 2) with device $V_{\text {oc }}$ values measured from the $I-V$ data (Table 1 ), the $V_{\text {oc }}$ data from CDCA devices have been used based on the assumption that CDCA treatment should mitigate dye aggregation and recombination losses. The data show the highest $V_{\text {oc }}$ values measured are for (5) and (7) and these dyes have the highest dye band gaps (2.60 and $2.67 \mathrm{eV}$ ). By comparison, the lowest $V_{\mathrm{oc}}$ is recorded is for (11) which also has the lowest band bap; $V_{\mathrm{oc}}=0.64 \mathrm{~V}$ and $E_{\mathrm{B}}=2.14 \mathrm{eV}$. This suggests that higher dye band gaps do result in higher $V_{\mathrm{oc}}$. However, the dye energy levels will set the maximum $V_{\text {oc }}$ and, as shown with the data from the CDCA treatment, voltage losses must be minimised to achieve this.

DFT molecular modelling studies of (4), (5), (8), (10) and (11) have also been carried out to study both the optimized molecular geometry and HOMO and LUMO maps of these dyes (Fig. 7). Whilst it is important to note that these are effectively gas phase structures (i.e. solvent free), for vinyl dicyano modified dyes ((4), (8) and (11)) the nitrile groups are consistently located on the same side of the molecule as the propionic acid linker. This implies that, if these dyes chemisorb through the indole propionate, the vinyl dicyano group is located closer to the $\mathrm{TiO}_{2}$ surface than the acid unit of the squaraine moiety. This is supported by the ATR-IR data for these dyes which show significant nitrile shifts on sorption to $\mathrm{TiO}_{2}$. In addition, the

Table 2 Band gaps $\left(E_{\mathrm{B}}\right)$ for selected Hf-SQ dyes measured from the onsets of UV-vis absorption data and from the mid-wave values or onsets of the cyclic voltammetry peaks and compared with values from DFT calculations. Units are eV unless stated

\begin{tabular}{lllllll}
\hline & \multicolumn{2}{l}{ Onset values } & & & \multicolumn{2}{l}{ Half-wave values } \\
\cline { 2 - 3 } Dye & $\lambda / \mathrm{nm}$ & $\lambda$ & From CV & From CV & From DFT \\
\hline$(4)$ & 526 & 2.35 & 2.30 & & 2.70 & 2.70 \\
$(5)$ & 476 & 2.60 & 2.55 & & 2.80 & 2.40 \\
$(7)$ & 464 & 2.67 & 2.57 & & - & - \\
$(\mathbf{8})$ & 508 & 2.44 & 2.37 & & 2.75 & 2.80 \\
$(\mathbf{1 0})$ & 544 & 2.28 & 2.30 & & 2.40 & 2.50 \\
$(\mathbf{1 1})$ & 580 & 2.14 & 2.15 & & 2.80 & 2.80
\end{tabular}

HOMO-LUMO calculations show electron density spread through the $\pi$-framework of each dye but not on the propionic acid linker. This suggests that the latter group acts mainly as a dye- $\mathrm{TiO}_{2}$ anchoring point and does not play a major role in electron injection from the dye excited state. This correlates well with the UV-vis data which suggests that the indole propionate is not strongly involved with the dye HOMO or LUMO levels. Analysis of the HOMO-LUMO energy level calculations shows that the band gaps are in good agreement with the mid-wave $\mathrm{CV}$ data apart from for (5) where there is closer agreement to the UV-vis onset value. This may reflect that the DFT relates to gas phase structures. Interestingly, when considering the relative energies of the HOMO and LUMO levels, the dyes are divided into 2 groups with the vinyl dicyano modified dyes much higher in energy. If these differences occurred for sorbed dyes, this might result in poorer overlap between dye and $\mathrm{TiO}_{2}$ orbitals which might result in poorer electron injection. This might explain why these dyes performed less well than expected in DSC devices. This is further supported when comparing the HOMO and LUMO maps of (4) and (5). For (4), the LUMO map shows little electron density near the vinyl dicyano-modified squaraine or propionic acid groups which are expected to be closest to $\mathrm{TiO}_{2}$. By comparison, (5) is the best performing dye and the LUMO map shows electron density on the squaraine moiety which would be expected to enhance electron injection for this dye.

\section{Experimental}

\section{Instrumentation and chemicals}

All chemicals were purchased from Aldrich and used as supplied unless otherwise stated. Anhydrous solvents were used as supplied except tetrahydrofuran (THF) which was dried using Na wire. NMR spectra were recorded on a Bruker AC500 at 500 $\mathrm{MHz}$ for ${ }^{1} \mathrm{H}$ and $125 \mathrm{MHz}$ for ${ }^{13} \mathrm{C}$. Chemical shifts $(\delta)$ are given in ppm relative to $\left(\mathrm{CH}_{3}\right)_{4} \mathrm{Si}$ and $J$ values (in $\mathrm{Hz}$ ) refer to $J_{\mathrm{H}, \mathrm{H}}$ unless otherwise stated. Mass spectra were recorded at the EPSRC National Mass Spectrometry Service at the University of Swansea. Infrared spectra were recorded on a PE1600 series FTIR spectrometer using an ATR attachment. UV-visible spectroscopy was measured on a Perkin Elmer spectrometer. Cyclic voltammetry was measured on $10 \mathrm{mM}$ dyes in $\mathrm{N}_{2}$-saturated DMF at RT using $0.1 \mathrm{M} \mathrm{Bu}_{4} \mathrm{NPF}_{6}$ as supporting electrolyte on an Autolab PGSTAT 30 computer-controlled electrochemical measurement system (Eco Chemie, Holland). Sweep rate was $50 \mathrm{mV} \mathrm{s}^{-1}$ in a 3-electrode cell using a glassy carbon $\left(1 \mathrm{~cm}^{2}\right)$ working electrode, a $\mathrm{Ag} / \mathrm{AgCl}$ reference electrode and a $\mathrm{Pt}$ counter electrode $\left(1 \mathrm{~cm}^{2}\right)$. All voltammetric potentials were re-calculated and are reported versus NHE.

\section{X-ray crystallography}

Single-crystal X-ray diffraction data of (4), (5), (7), (8) (polymorph 1) and (8) (polymorph 2) were collected at $100 \mathrm{~K}$ on Rigaku AFC12 goniometer equipped with an enhanced sensitivity (HG) Saturn 724 + detector mounted at the window of an 


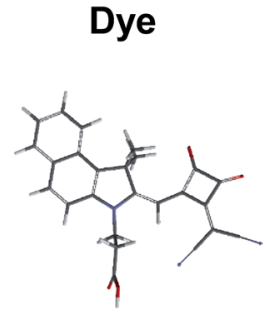

(4)

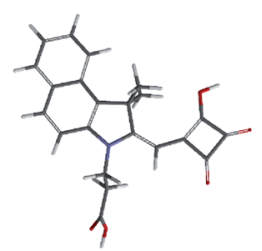

(5)

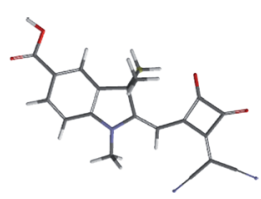

(8)

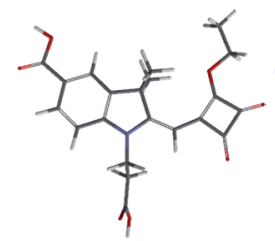

(10)

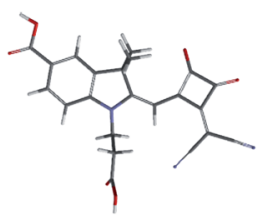

(11)
HOMO

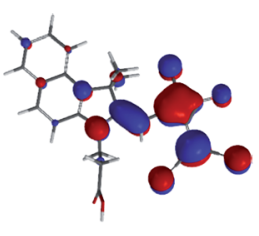

$-1.9 \mathrm{eV}$

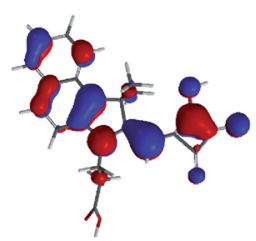

$-5.3 \mathrm{eV}$

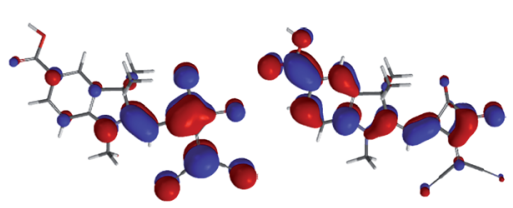

$-2.0 \mathrm{eV}$

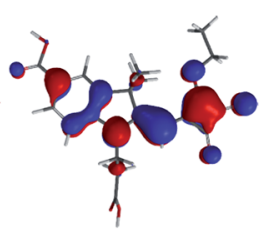

$-5.5 \mathrm{eV}$

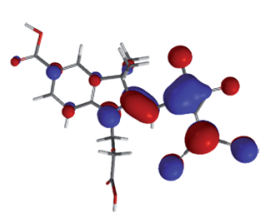

$-2.1 \mathrm{eV}$

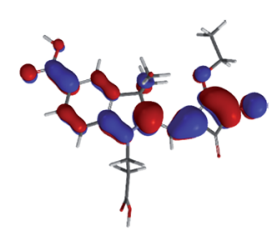

$-2.0 \mathrm{eV}$

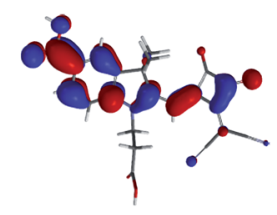

$0.7 \mathrm{eV}$
Fig. 7 Optimized geometries and HOMO-LUMO maps of selected dyes using $\mathrm{CH}_{3}$-indoline derivatives to simplify DFT calculations.

FR-E+ Superbright MoK rotating anode generator with HF Varimax optics. ${ }^{37}$

Unit cell parameters were refined against all data. An empirical absorption correction was carried out using CrystalClear software. ${ }^{38}$ All crystal structures were solved by charge flipping methods ${ }^{39}$ and refined on $F_{\mathrm{o}}{ }^{2}$ by full-matrix leastsquares refinements using programs of the SHELX-2013 software. ${ }^{40}$ All non-hydrogen atoms were refined with anisotropic displacement parameters. All hydrogen atoms were added at calculated positions and refined using a riding model with isotropic displacement parameters based on the equivalent isotropic displacement parameter $\left(U_{\text {eq }}\right)$ of the parent atom.

In the crystal structure of (4), the $\mathrm{HNEt}_{3}{ }^{+}$cation is disordered and modelled over two sites with a $78: 22$ ratio, whereas in (7) disordered ethoxy group on one of two independent molecules present in the asymmetric unit was modelled over two sites with $68: 32$ ratio. In (8) (polymorph 2), the aliphatic chain is badly disordered and modelled and constrained over two sites with a $72: 28$ ratio.

Vibrational restraints (SIMU/DELU) as well as distance/angle restraints DFIX/DANG were used to maintain sensible molecular geometry and atomic displacement ellipsoids. Some disordered atoms required EADP and ISOR restraints to be used.

Due to the poor crystal quality, data and highly disordered model obtained for (8) (polymorph 2), the solution for these data are not ideal. However, it is still sufficient to prove structural connectivity. $\dagger$

4. $a=13.6592(4) \AA, b=16.7465(5) \AA, c=23.9171(16) \AA, \alpha=\beta$ $=\gamma=90^{\circ} ; V=5470.9(4) \AA^{3}$, Orthorhombic, $P b c a, Z=8, \rho_{\text {calc }}=$ $1.279 \mathrm{Mg} \mathrm{m}^{-3} ; \mu=0.086 \mathrm{~mm}^{-1} ; T=100 \mathrm{~K} ; \theta_{\max }=27.48^{\circ}, 69549$ measured reflections, 6256 unique reflections $\left[R_{\text {int }}=0.0682\right]$, 4361 with $F^{2}>2 \sigma, R\left(F, F^{2}>2 \sigma\right)=0.0477 ; R_{\mathrm{w}}\left(F^{2}\right.$, all data $)=$ 0.1168; CCDC: 1030510 .

5. $a=13.654(3) \AA, b=17.014(3) \AA, c=16.253(3) \AA, \alpha=90^{\circ}, \beta$ $=109.290(2)^{\circ}, \gamma=90^{\circ} ; V=3559.8(12) \AA^{3}$, Monoclinic, $P 2_{1} / n, Z=$ $4, \rho_{\text {calc }}=1.155 \mathrm{Mg} \mathrm{m}^{-3} ; \mu=0.076 \mathrm{~mm}^{-1} ; T=100(2) \mathrm{K} ; \theta_{\max }=$ $27.506^{\circ}, 24283$ measured reflections, 8162 unique reflections $\left[R_{\mathrm{int}}=0.0596\right], 4856$ with $F^{2}>2 \sigma, R\left(F, F^{2}>2 \sigma\right)=0.0592 ; R_{\mathrm{w}}\left(F^{2}\right.$, all data) $=0.1351$; CCDC: 1030511 .

7. $a=9.8804(17) \AA, b=16.659(3) \AA, c=18.091(3) \AA, \alpha=$ $75.4470(10)^{\circ}, \beta=81.260(11)^{\circ}, \gamma=74.709(9)^{\circ} ; V=2768.4(8) \AA^{3}$, Triclinic, $P \overline{1}, Z=4, \rho_{\text {calc }}=1.189 \mathrm{Mg} \mathrm{m}^{-3} ; \mu=0.080 \mathrm{~mm}^{-1} ; T=$ $100(2) \mathrm{K} ; \theta_{\max }=27.528^{\circ}, 37607$ measured reflections, 12648 unique reflections $\left[R_{\text {int }}=0.1004\right], 7291$ with $F^{2}>2 \sigma, R\left(F, F^{2}>2 \sigma\right)$ $=0.0646 ; R_{\mathrm{w}}\left(F^{2}\right.$, all data $)=0.1746 ;$ CCDC: 1030512 .

8 (polymorph 1). $a=11.3712(6) \AA, b=12.1738(6) \AA, c=$ $14.8030(10) \AA, \alpha=105.290(7)^{\circ}, \beta=92.938(7)^{\circ}, \gamma=113.173(8)^{\circ}$; $V=1789.2(2) \AA^{3}$, Triclinic, $P \overline{1}, Z=2, \rho_{\text {calc }}=1.145 \mathrm{Mg} \mathrm{m}^{-3} ; \mu=$ $0.074 \mathrm{~mm}^{-1} ; T=100(2) \mathrm{K} ; \theta_{\max }=27.485^{\circ}, 31053$ measured reflections, 8194 unique reflections $\left[R_{\text {int }}=0.0882\right], 5922$ with $F^{2}$ $>2 \sigma, R\left(F, F^{2}>2 \sigma\right)=0.0617 ; R_{\mathrm{w}}\left(F^{2}\right.$, all data $)=0.0836$; CCDC: 1030513.

8 (polymorph 2). $a=8.358(3) \AA, b=10.369(4) \AA, c=$ $22.108(8) \AA, \alpha=98.940(6)^{\circ}, \beta=91.829(5)^{\circ}, \gamma=111.105(7)^{\circ} ; V=$ 1757.7(11) $\AA^{3}$, Triclinic, $P \overline{1}, Z=2$, calc $=1.165 \mathrm{Mg} \mathrm{m}^{-3} ; \mu=$ $0.076 \mathrm{~mm}^{-1} ; T=100(2) \mathrm{K} ; \theta_{\max }=25.026^{\circ}, 18323$ measured reflections, 6166 unique reflections $\left[R_{\text {int }}=0.0845\right], 3532$ with $F^{2}$ $>2 \sigma, R\left(F, F^{2}>2 \sigma\right)=0.1184 ; R_{\mathrm{w}}\left(F^{2}\right.$, all data $)=0.3751$; CCDC: 1030514 .

Preparation of triethylammonium-2-[(2-carboxyethyl-3,3dimethyl-1,3-dihydro-2H-indol-2-ylidene)]-3(dicyanomethylidene)-4-oxocyclobut-1-en-1-olate (4)

Triethylamine $(0.33 \mathrm{ml}, 2.38 \mathrm{mmol})$ was added dropwise to a mixture of (3) ( $0.81 \mathrm{~g}, 2 \mathrm{mmol})$ and malononitrile (145 mg, 2.22 $\mathrm{mmol})$ in ethanol $(15 \mathrm{ml})$ and stirred for $2 \mathrm{~h}$ at room temperature. The solvent was removed in vacuo and the product was obtained as an orange solid after purification by column chromatography $\left(\mathrm{SiO}_{2}\right)$ with chloroform and methanol as eluent. 
(Yield $1 \mathrm{~g}, 75 \%$ ) m.p. $175-179{ }^{\circ} \mathrm{C} . \delta_{\mathrm{H}}(400 \mathrm{MHz}, \mathrm{MeOD}) 8.11$ (1H, d, J 8.4), 7.89-7.80 (3H, m), 7.53-7.41 (2H, m), $7.32(1 \mathrm{H}, \mathrm{t}, J$ 7.4), 4.25 (2H, bs), 3.24 (6H, q, J 7.3), $2.80(2 \mathrm{H}, \mathrm{t}, J 6.4), 1.93(6 \mathrm{H}$, s), 1.33 (9H, t, $J$ 7.3).

$\delta_{\mathrm{C}}(101 \mathrm{MHz}, \mathrm{MeOD}) 191.78,191.28,185.69,181.53,173.25$, 138.03, 130.69, 130.12, 129.36, 128.99, 128.65, 127.93, 126.43, 125.99, 122.82, 122.40, 121.73, 112.87, 109.97, 38.39, 30.99, 26.07, 7.93.

MS (FTMS + ) $\mathbf{M}^{+}$calculated $=424, \mathbf{M}^{+}$observed $=424, \mathrm{~m} / \mathrm{z}$ accurate mass (FTMS+), reference compound: $\mathrm{NH}_{4} \mathrm{OAc}, \mathrm{M}^{+}$ calculated $=424.1292, \mathrm{M}^{+}$observed $=424.1294$. FT-IR $($ ATR $) \nu /$ $\mathrm{cm}^{-1} 3141$ (s), 2982 (s), 2685 (s), 2515 (s), 2197 (s), 2178 (s), 1732 (s), 1626 (s), 1595 (s), 1537 (s), 1517 (s). UV-visible $\lambda_{\max } 467 \mathrm{~nm}$ $\left(47000 \mathrm{M}^{-1} \mathrm{~cm}^{-1} \pm 500 \mathrm{M}^{-1} \mathrm{~cm}^{-1}\right.$ ) in ethanol.

\section{Preparation of 4-[(1-carboxy-1,3-dihydro-3,3-dimethyl-2H-} benzo[e]indol-2-ylidene)methyl]-3-cyclobutene-1,2-dione (5)

3-Ethoxy-[(1-carboxyethyl)-1,1,2-trimethyl-1 $H$-benzo[ $e]$ indolium iodide-2-ylidene)methyl]-3-cyclobutene-1,2-dione (1.07 g, 2.7 $\mathrm{mmol})$ was dissolved in ethanol $(10 \mathrm{ml})$ and heated under reflux. Tetrabutyl ammonium hydroxide ( $1 \mathrm{ml}, 40 \%$ ) was added and the solution was refluxed for $10 \mathrm{~min}$. The mixture was concentrated and $15 \mathrm{ml}$ of cold ethanol was added. The yellow product crystallized and was washed with ethanol three times.

Yield $0.5 \mathrm{~g}(50 \%)$ m.p. $185-191{ }^{\circ} \mathrm{C}$.

$\delta_{\mathrm{H}}(400 \mathrm{MHz}, \mathrm{MeOD}) 8.12(1 \mathrm{H}, \mathrm{d}, J$ 8.6), 7.83 (2H, dd, $J$ 11.4, 8.6), 7.51-7.43 (2H, m), 7.28 (1H, t, $J$ 7.5), 5.77 (1H, s), 4.29-4.21 (2H, m), 3.29-3.19 (10H, m), 2.68-2.60 (2H, m), 1.95 (6H, s), 1.67 (10H, dt, J 15.9, 7.9), 1.50-1.35 (8H, m), 1.03 (8H, t, $J$ 7.3).

$\delta_{\mathrm{C}}(101 \mathrm{MHz}, \mathrm{MeOD}) 204.15,196.50,179.97,177.48,164.56$, 140.82, 130.72, 130.34, 129.33, 128.88, 126.09, 122.19, 121.66, 109.93, 82.58, 58.13, 58.11, 58.08, 39.72, 34.14, 26.23, 23.39, $19.32,19.30,12.55$.

MS (FTMS + ) $\mathbf{M}^{+}$calculated $=270, \mathbf{M}^{+}$observed $=270, \mathrm{~m} / \mathrm{z}$ accurate mass (FTMS+), reference compound: $\mathrm{NH}_{4} \mathrm{OAc}, \mathrm{M}^{+}$ calculated $=270.1125, \mathrm{M}^{+}$observed $=270.1126$.

FT-IR (ATR) $\nu / \mathrm{cm}^{-1} 3512(\mathrm{w}), 2960$ (s), 2937 (s), 2876 (s), 1751 (m), 1666 (w), 1623 (m), 1592 (s), 1548 (s), 1516 (s). UV-visible $\lambda_{\max } 443 \mathrm{~nm}\left(18400 \mathrm{M}^{-1} \mathrm{~cm}^{-1} \pm 200 \mathrm{M}^{-1} \mathrm{~cm}^{-1}\right)$ in ethanol.

\section{Preparation of 5-carboxy-2,3,3-trimethyl-1-dodecyl-3H- indolium iodide (6)}

A mixture of 5-carboxy-2,3,3-trimethyl-3H-indolium iodide ( $2 \mathrm{~g}$, $6 \mathrm{mmol}$ ) and iodododecane $(4.1 \mathrm{~g}, 24 \mathrm{mmol})$ was heated under reflux overnight under nitrogen in anhydrous acetonitrile (80 $\mathrm{ml}$ ). After cooling, the solvent was removed in vacuo and the product was re-crystallized from methanol to give a yellow solid. (Yield $2.42 \mathrm{~g}, 72 \%$ ).

MS (FTMS + ) $\mathbf{M}^{+}$calculated $=372, \mathbf{M}^{+}$observed $=372 . \mathrm{m} / \mathrm{z}$ accurate mass (FTMS+), reference compound: $\mathrm{NH}_{4} \mathrm{OAc}, \mathrm{M}^{+}$ calculated $=372.2897, \mathrm{M}^{+}$observed $=372.887$.

Preparation of 2-((2-ethoxy-3,4-dioxocyclobut-1-enyl)methylene)3,3-dimethyl-1-dodecylindoline-5-carboxylic acid (7)

Synthetic procedures followed to (3).

(2 g, 65\%) m.p. $180-184{ }^{\circ} \mathrm{C}$.
$\delta_{\mathrm{H}}(400 \mathrm{MHz}, \mathrm{THF})$ 8.04-8.02 (doublet and singlet overlapping $3 \mathrm{H}), 7.10(1 \mathrm{H}, \mathrm{d}, J$ 8.2), $5.58(1 \mathrm{H}, \mathrm{s}), 4.92(2 \mathrm{H}, \mathrm{q}, J 7.1)$, $3.98(2 \mathrm{H}, \mathrm{t}, J 7.4), 3.65(1 \mathrm{H}, \mathrm{s}), 1.71$ (6H, s), $1.56(3 \mathrm{H}, \mathrm{t}, J 7.1), 1.48$ $(4 \mathrm{H}, \mathrm{m}), 1.35(14 \mathrm{H}, \mathrm{s}), 0.95(3 \mathrm{H}, \mathrm{t}, J 6.6)$.

$\delta_{\mathrm{C}}(101 \mathrm{MHz}, \mathrm{THF}) 189.65,187.42,185.97,171.22,164.78$, 164.58, 144.90, 138.61, 128.58, 122.74, 121.28, 105.69, 80.66, $67.84,45.19$, 40.59, 30.02, 27.73, 27.67, 27.62, 27.45, 27.44, 24.93, 24.51, 24.29, 20.71, 13.33, 11.61 .

MS (FTMS-) $[\mathrm{M}-\mathrm{H}]^{-}$calculated $=494,[\mathrm{M}-\mathrm{H}]^{-}$observed $=494 . \mathrm{m} / \mathrm{z}$ accurate mass $\left(\right.$ FTMS - ), $[\mathrm{M}-\mathrm{H}]^{-}$calculated $=$ 494.2912, $[\mathrm{M}-\mathrm{H}]^{-}$observed $=494.2919$.

FT-IR (ATR) $\nu / \mathrm{cm}^{-1} 3065$ (b), 2925 (s), 2856 (s), 2530 (b), 1773 (s), 1716 (s), 1678 (s), 1603 (s), 1539 (s). UV-visible $\lambda_{\max } 428 \mathrm{~nm}$ $\left(78000 \mathrm{M}^{-1} \mathrm{~cm}^{-1} \pm 700 \mathrm{M}^{-1} \mathrm{~cm}^{-1}\right.$ ) in ethanol.

Preparation of 2-((2-ethoxy)methylene)-3,3-dimethyl-1dodecylindoline-3-(dicyanomethylidene)-5-carboxylic acid (8)

Synthetic procedures followed to (4).

Yield $0.8 \mathrm{~g}(70 \%)$ m.p. $170-175{ }^{\circ} \mathrm{C}$.

$\delta_{\mathrm{H}}(400 \mathrm{MHz}, \mathrm{MeOD}) 7.98(1 \mathrm{H}, \mathrm{d}, J$ 8.3), $7.90(1 \mathrm{H}, \mathrm{s}), 6.99(1 \mathrm{H}$, $\mathrm{d}, J$ 8.3), $6.14(1 \mathrm{H}, \mathrm{s}), 3.86(2 \mathrm{H}, \mathrm{t}, J 7.0), 3.24(6 \mathrm{H}, \mathrm{m}), 1.75(2 \mathrm{H}, \mathrm{d}$, $J$ 6.6), 1.68 (6H, s), $1.32(24 \mathrm{H}, \mathrm{m}), 0.91(3 \mathrm{H}, \mathrm{t}, J 6.3)$.

$\delta_{\mathrm{C}}(101 \mathrm{MHz}, \mathrm{MeOD}) 192.35,185.79,178.53,168.78,167.78$, 163.87, 147.41, 140.60, 130.48, 123.27, 122.81, 118.66, 117.84, 107.01, 86.06, 42.47, 41.36, 37.18, 35.58, 31.67, 29.32, 29.08, $29.04,28.97,27.91,26.47,26.21,26.14,23.01,22.33,17.98$, 13.06, 8.46, 7.85 .

MS (FTMS - ) $[\mathrm{M}]^{-}$calculated $=514,[\mathrm{M}]^{-}$observed $=514 \mathrm{~m} / \mathrm{z}$ accurate mass (FTMS - ), $[\mathrm{M}]^{-}$calculated $=514.2711,[\mathrm{M}]^{-}$ observed $=514.2699$.

FT-IR (ATR) $\nu / \mathrm{cm}^{-1} 3158$ (bs), 2925 (s), 2854 (s), 2639 (bs), 2201 (s), 2182 (s), 1749 (s), 1705 (s), 1666 (s), 1618 (m), 1604 (m), 1533 (s). UV-visible $\lambda_{\max } 466 \mathrm{~nm}\left(55000 \mathrm{M}^{-1} \mathrm{~cm}^{-1} \pm 600 \mathrm{M}^{-1}\right.$ $\mathrm{cm}^{-1}$ ) in ethanol.

\section{Preparation of 5-carboxy-2,3,3-trimethyl-1-carboxyethyl-3H- indolium iodide (9)}

A mixture of 5-carboxy-2,3,3-trimethyl-3 $H$-indolium iodide ( $2 \mathrm{~g}$, $6 \mathrm{mmol}$ ) and 3-iodopropionic acid (2 g, $7.5 \mathrm{mmol}$ ) was heated under reflux overnight under nitrogen in anhydrous 1,2 dichlorobenzene $(30 \mathrm{ml})$. After cooling, the solvent was removed in vacuo and the product was re-crystallized from methanol to give a yellow solid. (Yield $1.67 \mathrm{~g}, 70 \%$ ).

MS (FTMS+) $\mathbf{M}^{+}$calculated $=276, \mathbf{M}^{+}$observed $=276, \mathrm{~m} / \mathrm{z}$ accurate mass (FTMS + ), reference compound: $\mathrm{NH}_{4} \mathrm{OAc}, \mathrm{M}^{+}$ calculated $=276.1230, \mathrm{M}^{+}$observed $=276.1227$.

\section{Preparation of 2-((2-ethoxy-3,4-dioxocyclobut-1-enyl)} methylene)-3,3-dimethyl-1-carboxyethylindoline-5-carboxylic acid (10)

Synthetic procedures followed (3).

Yield $0.5 \mathrm{~g}$ (80\%) m.p. $180-185^{\circ} \mathrm{C}$.

$\delta_{\mathrm{H}}(400 \mathrm{MHz}, \mathrm{MeOD})$ 8.04-7.97 (doublet and singlet overlapping 3H), 7.20 (1H, d, J 8.3), $6.02(1 \mathrm{H}, \mathrm{s}), 4.44$ (3H, t, $J$ 6.7), 4.27-4.20 (two overlapping triplets $4 \mathrm{H}$ ), 4.17 (3H, t, $J$ 7.4), 3.20 (2H, q, J 7.3), 1.66 (6H, s). 
$\delta_{\mathrm{C}}(101 \mathrm{MHz}, \mathrm{MeOD}) 196.95,191.89,179.38,177.80,170.28$, $167.43,161.47,147.39,145.20,140.18,129.77,122.63,108.18$, 106.88, 84.29, 69.90, 39.13, 32.26, 28.79, 25.94, 14.62.

MS (FTMS-) $[\mathrm{M}-\mathrm{H}]^{-}$calculated $=398,[\mathrm{M}-\mathrm{H}]^{-}$observed $=398 . \mathrm{m} / \mathrm{z}$ accurate mass $(\mathrm{FTMS}-),[\mathrm{M}-\mathrm{H}]^{-}$calculated $=$ 398.1245, $[\mathrm{M}-\mathrm{H}]^{-}$observed $=398.1235$.

FT-IR (ATR) $\nu / \mathrm{cm}^{-1} 3543-3060(\mathrm{bs}), 2978(\mathrm{w}), 2965(\mathrm{~m})$, 2866 (s), 1738 (s), 1707 (s), 1618 (s), 1554 (s). UV-visible $\lambda_{\max }$ $425 \mathrm{~nm}\left(16000 \mathrm{M}^{-1} \mathrm{~cm}^{-1} \pm 400 \mathrm{M}^{-1} \mathrm{~cm}^{-1}\right)$ in ethanol.

Preparation of 2-((2-ethoxy)methylene)-3,3-dimethyl-1carboxyethylindoline-3-(dicyanomethylidene)-5-carboxylic acid (11)

Synthetic procedures followed (4).

Yield $0.3 \mathrm{~g}(60 \%) \mathrm{m} . \mathrm{p} .170-175{ }^{\circ} \mathrm{C}$.

$\delta_{\mathrm{H}}(400 \mathrm{MHz}, \mathrm{MeOD}) 7.96(1 \mathrm{H}, \mathrm{d}, J 8.3), 7.89$ (1H, d, $\left.J 1.0\right)$, 7.10 (1H, d, $J$ 8.4), $6.10(1 \mathrm{H}, \mathrm{s}), 4.17(2 \mathrm{H}, \mathrm{t}, J 6.8), 3.23(6 \mathrm{H}, \mathrm{q}$, $J$ 7.3), 2.75 (2H, t, $J$ 6.8), 1.68 (6H, s), 1.33 (12H, t, $J$ 7.3).

$\delta_{\mathrm{C}}(101 \mathrm{MHz}, \mathrm{MeOD}) 192.58,185.94,179.98,173.74,168.71$, 163.04, 147.08, 140.16, 130.42, 123.55, 118.47, 117.57, 111.91, 106.87, 86.20, 68.02, 40.39, 38.80, 30.98, 26.60, 22.17, 18.40, $9.98,7.40$.

MS (FTMS -$)[\mathrm{M}]^{-}$calculated $=418,[\mathrm{M}]^{-}$observed $=418 . \mathrm{m} /$ $z$ accurate mass (FTMS - ), $[\mathrm{M}]^{-}$calculated $=418.1045,[\mathrm{M}]^{-}$ observed $=418.1036$.

FT-IR (ATR) $\nu / \mathrm{cm}^{-1} 3420$ (b), 2988 (w), $2974(\mathrm{w}), 2924(\mathrm{w})$, 2500 (b), 2198 (s), 1744 (s), 1681 (s), 1603 (s), 1544 (s). UV-visible $\lambda_{\max } 459 \mathrm{~nm}\left(2500 \mathrm{M}^{-1} \mathrm{~cm}^{-1} \pm 60 \mathrm{M}^{-1} \mathrm{~cm}^{-1}\right)$ in ethanol.

\section{Device manufacture and testing}

DSC devices were prepared using $1.0 \mathrm{~cm}^{2}(2 \times 0.5 \mathrm{~cm}) \mathrm{TiO}_{2}$ working electrodes by doctor blading two layers of transparent paste (DSL18NR-T, Dyesol) onto TEC15 ${ }^{\mathrm{TM}}$ FTO glass (NSG) followed by one layer of scattering paste (WER4-O, Dyesol). Each layer was sintered $\left(450{ }^{\circ} \mathrm{C}, 30 \mathrm{~min}\right)$ before $\mathrm{TiCl}_{4}: \mathrm{THF}_{2(\mathrm{aq})}$ treatment $\left(50 \mathrm{mM}, 70{ }^{\circ} \mathrm{C}, 30 \mathrm{~min}\right)$, rinsing with de- $\mathrm{H}_{2} \mathrm{O}$ and resintering $\left(450{ }^{\circ} \mathrm{C}, 30 \mathrm{~min}\right)$. To prepare counter electrodes, after washing $\left({ }^{\mathrm{i}} \mathrm{PrOH}\right)$ and air drying TEC ${ }^{\mathrm{TM}}$ glass (NSG) Pt colloid (Pt-1, Dyesol) was deposited and then sintered $\left(400{ }^{\circ} \mathrm{C}, 30 \mathrm{~min}\right)$. After sealing the counter and working electrodes together with Surlyn $^{\mathrm{TM}}$ (DuPont) at $120{ }^{\circ} \mathrm{C}$, the devices were fast dyed according to the method described previously ${ }^{41}$ after which acetonitrile-based electrolyte was added (50 $\mathrm{mM} \mathrm{I}_{2}, 50 \mathrm{mM} \mathrm{LiI}$, $50 \mathrm{mM}$ guanidinium thiocyanate, $800 \mathrm{mM}$ 1-methyl-3-propylimidazolium iodide, $300 \mathrm{mM}$ benzimidazole). Conductive $\mathrm{Ag}$ paint (Agar) was applied to ensure good electrical contact.

Device performance was measured using $I-V$ data and an ABET Solar Simmulator with Xe arc lamp and Keithley 2400 at $100 \mathrm{~mW} \mathrm{~cm}^{-2}$ or 1 Sun between 0 and $1 \mathrm{~V}$. Spectral response was measured in DC mode using a QEX10 Quantum Efficiency Measurement System (resolution $10 \mathrm{~nm}$ ). Lamp calibration to 1 Sun (100 $\mathrm{mW} \mathrm{cm}^{-2}$ ) used a certified (Oriel 91150V) monocrystalline silicon reference cell traceable to the National Renewable Energy Laboratory (NREL).

\section{Molecular modeling}

DFT calculations to predict the geometries and properties of the dyes were performed using a 64 bit version of Spartan' $14 .{ }^{42}$ The structures were first optimized semi-empirically (AM1) and then re-optimized using B3LYP (6-31G*). Frequency calculations confirmed the optimizations gave rise to local minima. To facilitate geometry optimization, some of the longer side-chains were shortened to methyl groups.

\section{Conclusions}

This study shows that increasing the number of linker groups for Hf-SQ dyes improves DSC device efficiency leading to the highest efficiency reported for this class of sensitizer. Furthermore, increasing the number of linker groups enables the favourable optical properties of a vinyl dicyano modified squaric acid dye to be retained whilst also ensuring that the dye does not desorb from the electrode surface during electrolyte infusion. However, the data support previous studies ${ }^{35}$ which suggest that the position of linker groups in the dye molecule is important and that they need to be positioned to enable the LUMO of the dye to be in close proximity to the $\mathrm{TiO}_{2}$ surface.

Our data also show that infrared spectroscopy can be used to study dye sorption from the different linker groups. These data suggest that, to optimize DSC device performance, it is necessary to place the second linker closer to the squaraine unit. If this happens, it appears that the squaraine moiety can orient itself closer to the $\mathrm{TiO}_{2}$ which is believed to be a better position to enable electron injection from the dye excited state into the $\mathrm{TiO}_{2}$. However, DFT calculations and ATR-IR data suggest that, for vinyl dicyano modified squaraines, the nitrile groups orient themselves closer to the $\mathrm{TiO}_{2}$ resulting in poorer than expected electron injection from this group of dyes. This explains the poor binding and device performance of $\left(\mathbf{8}^{\prime}\right)$ reported in. ${ }^{35}$ The DFT data also support our previous assertion ${ }^{35}$ that, for the best performing dyes, the LUMO is located near to the squaraine linker moiety. We are currently studying the long-term stability of these dyes but our initial data suggest that they are stable in DSC devices under ambient conditions in the short term (i.e. weeks).

\section{Acknowledgements}

We gratefully acknowledge Welsh Government funding for Sêr Cymru (AC, EWJ, CK, PJH), EPSRC/TSB funding for SPECIFIC (EP/I019278/1) for MLD, EPSRC CASE and Tata support for LF and the EPSRC UK National Mass Spectrometry Facility at Swansea University. We thank EPSRC for funding the National Crystallography Service (Southampton and Newcastle), and Diamond Light Source for access to synchrotron facilities.

\section{Notes and references}

1 B. O'Regan and M. Grätzel, Nature, 1991, 353, 737.

2 A. Hagfeldt, G. Boschloo, L. C. Sun, L. Kloo and H. Pettersson, Chem. Rev., 2010, 110, 6595. 
3 M. K. Nazeeruddin, F. De Angelis, S. Fantacci, A. Selloni, G. Viscardi, P. Liska, S. Ito, B. Takeru and M. Grätzel, J. Am. Chem. Soc., 2005, 127, 16835.

4 Y. Cao, Y. Bai, Q. Yu, Y. Cheng, S. Liu, D. Shi, F. Gao and P. Wang, J. Phys. Chem. C, 2009, 113, 6290.

5 K.-L. Wu, H.-C. Hsu, K. Chen, Y. Chi, M.-W. Chung, W.-H. Liu and P.-T. Chou, Chem. Commun., 2010, 46, 5124.

6 K. Cao, J. Lu, J. Cui, Y. Shen, W. Chen, G. Alemu, Z. Wang, H. Yuan, J. Xu, M. Wang and Y. Cheng, J. Mater. Chem. A, 2014, 2, 4945.

7 C.-Y. Chen, J.-G. Chen, S.-J. Wu, J.-Y. Li, C.-G. Wu and K.-C. Ho, Angew. Chem., Int. Ed., 2008, 47, 7342.

8 T. Funaki, N. O. Komatsuzaki, K. Kasuga, K. Sayama and H. Sugihara, Inorg. Chem. Commun., 2013, 35, 281.

9 T. Bessho, E. Yoneda, J.-H. Yum, M. Guglielmi, I. Tavernelli, H. Imai, U. Rothlisberger, M. K. Nazeeruddin and M. Grätzel, J. Am. Chem. Soc., 2009, 131, 5930.

10 K.-L. Wu, W.-P. Ku, S.-W. Wang, A. Yella, Y. Chi, S.-H. Liu, P.-T. Chou, M. K. Nazeeruddin and M. Grätzel, Adv. Funct. Mater., 2013, 23, 2285.

11 K.-L. Wu, W.-P. Ku, J. N. Clifford, E. Palomares, S.-T. Ho, Y. Chi, S.-H. Liu, P.-T. Chou, M. K. Nazeeruddin and M. Grätzel, Energy Environ. Sci., 2013, 6, 859.

12 G. C. Vougioukalakis, A. I. Philippopoulos, T. Stergiopoulos and P. Falaras, Coord. Chem. Rev., 2011, 255, 2602.

13 M. Wang, S.-J. Moon, D. Zhou, F. L. Formal, N. Lê, C. Ha, R. H. Baker, C. Grätzel, P. Wang, S. M. Zakeeruddin and M. Grätzel, Adv. Funct. Mater., 2010, 20, 1821.

14 K. Fantai, A. I. Songyuan and W. Kongj, Plasma Sci. Technol., 2006, 8, 5 .

15 A. J. Hallett and J. E. Jones, Dalton Trans., 2011, 40, 3871.

16 H. Im, S. Kim, C. Park, S.-H. Jang, C.-J. Kim, K. Kim, N.-G. Park and C. Kim, Chem. Commun., 2010, 46, 1335.

17 M. Liang and J. Chen, Chem. Soc. Rev., 2013, 42, 3453.

18 N. Mohammad, P. J. Mahon and F. Wang, J. Mol. Graphics Modell., 2013, 40, 64.

19 K. Hara, Z. S. Wang, T. Sato, A. Furube, R. Katoh, H. Sugihara, Y. D. Oh, C. Kasada, A. Shinpo and S. Suga, J. Phys. Chem. B, 2005, 109, 15476.

20 S. Ito, S. M. Zakeeruddin, R. Humphry-Baker, P. Liska, R. Charvet, P. Comte, M. K. Nazeeruddin, P. Pechy, M. Takata, H. Miura, S. Uchida and M. Grätzel, Adv. Mater., 2006, 18, 1202.

21 Y. Wu, M. Marszalek, S. M. Zakeeruddin, Q. Zhang, H. Tian, M. Grätzel and W. Zhu, Energy Environ. Sci., 2012, 5, 8261.
22 X. Lu, Q. Feng, T. Lan, G. Zhou and Z.-S. Wang, Chem. Mater., 2012, 24, 3179.

23 H. Hug, M. Bader, P. Mair and T. Glatzel, Appl. Energy, 2014, 115, 216.

24 N. A. Ludin, A. M. A. Mahmoud, A. B. Mohamad, A. A. H. Kadhum, K. Sopian and N. S. A. Karim, Renewable Sustainable Energy Rev., 2014, 31, 386.

25 Y.-S. Yen, H.-H. Chou, Y.-C. Chen, C.-Y. Hsu and J. T. Lin, J. Mater. Chem., 2012, 22, 8734.

26 P. J. Holliman, K. J. Al-Salihi, A. Connell, M. L. Davies, E. W. Jones and D. A. Worsley, RSC Adv., 2014, 4(5), 2515.

27 A. Yella, H.-W. Lee, H. N. Tsao, C. Yi, A. K. Chandiran, M. K. Nazeeruddin, E. W.-G. Diau, C.-Y. Yeh, S. M. Zakeeruddin and M. Grätzel, Science, 2011, 334, 629.

28 A. Yella, C.-L. Mai, S. M. Zakeeruddin, S.-N. Chang, C.-H. Hsieh, C.-Y. Yeh and M. Grätzel, Angew. Chem., Int. Ed., 2014, 53(11), 2973.

29 A. L. Tatarets, I. A. Fedyunyaeva, E. Terpetschnig and L. D. Patsenker, Dyes Pigm., 2005, 64, 125.

30 L. Beverina and P. Salice, Eur. J. Org. Chem., 2010, 1207.

31 M. Matsui, T. Shibata, M. Fukushima, Y. Kubota and K. Funabiki, Tetrahedron, 2012, 68, 9936.

32 M. Matsui, H. Mase, J.-Y. Jin, K. Funabiki, T. Yoshida and H. Minoura, Dyes Pigm., 2006, 70, 48.

33 N. Shahzad, F. Risplendi, D. Pugilese, S. Bianco, A. Sacco, A. Lamberti, R. Gazzia, E. Tresso and G. Cicero, J. Phys. Chem. C, 2013, 117, 22778.

34 G. Cicero, G. Musso, A. Lambertini, B. Camino, S. Bianco,

D. Pugilese, F. Risplendi, A. Sacco, N. Shahzad, A. M. Ferrari, B. Ballarin, C. Barolo, E. Tresso and G. Caputo, Phys. Chem. Chem. Phys., 2013, 15, 7198.

35 A. Connell, P. J. Holliman, M. L. Davies, C. D. Gwenin, S. Weiss, M. B. Pitak, P. N. Horton, S. J. Coles and G. Cooke, J. Mater. Chem. A, 2014, 2(11), 4055.

36 E. Terpetschnig and J. R. Lakowicz, Dyes Pigm., 1993, 21(3), 227.

37 S. J. Coles and P. A. Gale, Chem. Sci., 2012, 3, 683.

38 CrystalClear-SM Expert 3.1ba16, Rigaku, 2012.

39 L. Palatinus and G. Chapuis, J. Appl. Crystallogr., 2007, 40, 786.

40 G. M. Sheldrick, Acta Crystallogr., Sect. A: Found. Crystallogr., 2008, 64, 112.

41 P. J. Holliman, M. L. Davies, A. Connell, B. Vaca Velasco and T. M. Watson, Chem. Commun., 2010, 46, 7256.

42 Wavefunction, Inc. 18401 Von Karman Ave., Suite 370, Irvine, CA 92612. 